\title{
Habitat use and feeding ecology of Kulal White-eye Zosterops kulalensis
}

\author{
LUCA BORGHESIO and PAOLA LAIOLO
}

\begin{abstract}
Summary
Kulal White-eye Zosterops kulalensis is endemic to Mt Kulal, northern Kenya. It is currently considered a Vulnerable species because of its restricted range. We investigated its habitat and microhabitat use, and flocking and foraging behaviour, with respect to seasonal and diurnal variation. In the dry season, Kulal White-eye was encountered only in montane forest, where it was more abundant in glades than in closed-canopy habitats. Here it fed frequently on fruit, as most fruiting occurred in the drier months. In the wet season population density was also higher in glades than in closed-canopy forest, but birds were mostly insectivorous. Foraging in bush outside the forest was favoured. In the wet season, Kulal White-eye inhabited both the forest and the drier bush at lower altitudes, and avoided habitats with mature trees, preferring young tree formations where vegetation was thicker. Flock size was larger in the dry season, and, in the wet season, larger flocks were encountered in the morning and in late afternoon. Our study suggests that Kulal White-eye is less restricted to mature forest than previously thought. The conservation of the species requires that both the forest and the adjoining bush habitats receive adequate protection. Although some traditional human activities could be compatible with conservation, grazing of domestic animals inside the forest and the removal of large tracts of bush to create new pastures could be detrimental to the species.
\end{abstract}

\section{Introduction}

The Zosteropidae (white-eyes) is a remarkably homogeneous, Old World tropical family of small, gregarious, arboreal insectivores or frugivores/nectarivores. About seventy species are currently classified in the genus Zosterops. While most species are sedentary, white-eyes show a strong ability to fly considerable distances to colonise islands and speciate there: more than half of African species are offshore island endemics (Fry et al. 2001). Endemism also occurs in inland East Africa, where several mountain massifs contain small forest fragments surrounded by large areas of unsuitable arid habitats. These 'forest islands' support forms whose systematic status is still under debate, as the remarkable uniformity in plumage, size and behaviour makes the limits of the East-African species notoriously puzzling (Moreau 1957, Fry et al. 2001). Kulal White-eye Zosterops kulalensis was considered a good species by BirdLife International (2000), a subspecies of Yellow White-eye Zosterops senegalensis kulalensis by Howard and Moore (1991), or a subspecies of Montane White-eye Zosterops poliogastra kulalensis by Britton (1980). In this paper we adopt the systematics proposed by BirdLife International (2000), although we do not consider this to be a definitive treatment. 
Systematics apart, the tendency of many taxa in the Zosteropidae to be restricted to small insular habitats has exposed them to a high risk of extinction: twenty-six species of Zosteropidae are currently considered globally threatened (BirdLife International 200o). Owing to its very restricted distribution, Kulal White-eye was considered Critically Endangered in the IUCN criteria by Collar et al. (1994), but it was downlisted as Vulnerable by BirdLife International (2000). This species inhabits only a small patch of forest on the top of Mt Kulal, in northern Kenya. In 1998, the total population was tentatively estimated at about 10,000 individuals (Borghesio and Ndang'ang'a 1999). Kulal White-eye could face high risks of extinction in the medium-term future, since it is clear that with such a restricted range even a single catastrophic event could affect all the individuals of the species. As for other forest birds, it could also be threatened by habitat loss and degradation that might be particularly acute in a region where human density is steadily growing.

Apart from some small and mostly anecdotal contributions (Diamond and Keith 1980, Borghesio and Ndang'ang'a 1999, 2001), the ecology of Kulal Whiteeye is known only poorly. No quantitative study of patterns of habitat use and foraging behaviour have been carried out, and no data were previously available on seasonal movements or niche shifts of this species. Indeed, despite the obvious importance of these subjects for conservation, few studies in Africa have focused on the influence of seasonality and habitat changes on bird's movements and niche shifts. Various authors have reported the existence of seasonal habitat and altitudinal migration in African forest birds (Dowsett-Lemaire 1989, Lewis and Pomeroy 1989, Burgess and Mlingwa 2000), but only in a few cases have these movements been related to specific factors, such as food resource tracking (Whitney and Smith 1998).

The lack of this basic information seriously hampers any attempt at evaluation of the conservation status of the species, and especially in predicting the effects that human activity could have on its survival. In this study we investigated Kulal White-eye habitat requirements, focusing on habitat and microhabitat use, flocking and foraging behaviour. All these aspects were analysed with respect to wet and dry period extremes, as we expected that seasonality plays an important role in shaping this species' ecology. Diurnal cycles in micro-habitat use and flocking are also investigated.

\section{Study area}

The study area was located on Mt Kulal $\left(2^{\circ} 43^{\prime} \mathrm{N}, 36^{\circ} 56^{\prime} \mathrm{E}\right)$, an extinct volcano east of Lake Turkana, Kenya Northern Province. Despite being surrounded by flat zones where arid or semi-arid climate prevails, Mt Kulal receives enough precipitation (900-1,000 $\mathrm{mm} /$ year) to allow the growth of true forest vegetation on its top (Bake 1983). Rainfall is strongly bimodal, and occurs mostly in two rainy seasons (April-May and November). However, rainfall is unpredictable and highly variable from year to year (Edwards et al. 1979, Bake 1983). In the first part of our study, the area received exceptionally high rainfall during the El Niño event of September 1997-May 1998. In contrast, after May 1998, rainfall was extremely low, and during our second visit in October 1998 the area was very dry. 
Our study area varied from 1,400 $\mathrm{m}$ to $2,230 \mathrm{~m}$ a.s.l. (the mountain top). The main habitats in our study site were "forest" and "bush" (which respectively correspond to "Evergreen Forest" and "Evergreen to semi deciduous bushland" of Herlocker 1979). Forest began from an altitude of about $1,800 \mathrm{~m}$ and was dominated by trees with $>5 \mathrm{~cm}$ diameter at breast height (dbh) and a medium or low density of shrubs (vegetation of $1-3 \mathrm{~m}$ of height); canopy height averaged $13.2 \mathrm{~m} \pm 0.4 \mathrm{SE}(n=121$ sampling stations). Common tree species included Cassipourea malosana, Olea hochstetteri, Xymalos monospora, Teclea simplicifolia and T. nobilis. Juniperus procera and Olea europaea were also present, but usually in the outer and most disturbed parts of the forest.

As a result of human activity, which consists of extraction of fuelwood and building poles, grazing of domestic herbivores (cattle and goats) and wild honey collection (often involving the felling of single trees), several gaps and glades are interspersed within the forest. Forest fires are common but they usually affect only small (<1 ha) expanses of forest. We defined as bush all habitats with few or no trees, dominated by shrubs, and found at altitudes lower than $1,800 \mathrm{~m}$. Cadia purpurea, Euclea divinorum, Carissa edulis, and Myrsine africana are common in the wetter areas surrounding the forest, while several species of Acacia are dominant increasingly at lower elevations. Most human activity (agriculture and pastoralism) occurs in this habitat, where all human settlements are also found.

\section{Methods}

Point counts and habitat sampling

The study was carried out in November-December 1997 (wet period) and October 1998 (dry period). We used a fixed-radius point count census technique to survey the bird community of Mt Kulal (Borghesio and Ndang'ang'a 2001). For the purpose of this paper, only Kulal White-eye data were included in the analysis. One of us (LB) performed 271 point counts (173 in the wet season and 98 in the dry season) within suitable habitats in the study area. The location of the sample points was determined by walking at constant speed $(2-3 \mathrm{~km} / \mathrm{hr})$ along approximately linear routes and stopping after exactly six minutes of walking. All points were sampled once, between sunrise and 11hoo. Birds within a $25 \mathrm{~m}$ radius from the observer were counted during a $15 \mathrm{~min}$ period at each point.

At each individual census station, habitat data were collected after the completion of the bird count. We estimated percentage vegetation cover within $25 \mathrm{~m}$ radius plots centred on the census points. The vegetation was subdivided into four layers: ground/herb (o to $1 \mathrm{~m}$ ), shrub ( $>1$ to $3 \mathrm{~m}$ ), subcanopy (>3 to $8 \mathrm{~m}$ ), and canopy $(>8 \mathrm{~m})$. We also counted the number of trees (defined as woody plants $>3 \mathrm{~m}$ ) in three dbh classes: $0-5 \mathrm{~cm}, 5-20 \mathrm{~cm},>20 \mathrm{~cm}$; these three variables were recorded within $10 \mathrm{~m}$ radius around the census point. Within the forest, we always recorded if counts were performed in closed-canopy forest or in a glade, defined as a gap in the canopy with a diameter larger than $10 \mathrm{~m}$. Glades could not be identified in the bush habitat. In order to derive an estimate of fruit availability and fruit location, we also recorded the occurrence of fruiting plants and their height at each sampling point. 


\section{Observations of foraging birds}

When a foraging bird was seen, its height above ground, plant height and foraging substrate were recorded. All height measurements were done with a pocket rangefinder (Ranging Opti-meter ${ }^{\circledR}$ 120). Substrates from which food was taken were categorized as: air, trunks and boughs (inner branches, diameter $>5 \mathrm{~cm}$ ), branches (diameter $1-5 \mathrm{~cm}$ ), leaves, twigs (diameter $<1 \mathrm{~cm}$ ), lichens, mosses, flowers, fruit. Since behaviour of individuals in a flock is not independent, observations were made on only one randomly-chosen individual of a group. To avoid pseudoreplication, only the first sighting of each bird was recorded, thus sample sizes represent the number of individuals observed. Overall, 212 observations were collected (112 in the wet season and 100 in the dry).

Whenever possible, the number of foraging birds in the flock was also recorded, and a total of 129 such observations was made. All the individuals foraging on the same or nearby trees, arriving and departing together, were assumed to belong to the same flock.

Feeding rate was measured by timing a bird while it pecked and swallowed items. For each foraging individual we also recorded the size of the flock and the type of food items collected (fruit or invertebrates). We obtained data from 83 foraging individuals ( 48 in wet and 35 in dry season).

\section{Data analysis}

Since all seven habitat variables describing vegetation cover and tree abundance in the plots showed a high degree of intercorrelation (multicollinearity), much of the information in one or more of these variables was probably redundant and the results of a regression analysis in this case may be ambiguous (Jongman et al. 1995). We compensated for multicollinearity by summarizing the environmental attributes of the census plots with a principal component analysis (PCA), which condensed the original information on two derived axes ( $\mathrm{PC}_{1}$ and $\mathrm{PC}_{2}$ ) having the benefit of being orthogonal and uncorrelated. Before performing PCA, habitat data were transformed to attain mean $=0$ and unit standard deviation. Logistic regression analysis was used to describe the relationship between Kulal White-eye presence or absence and a set of explanatory variables that represented a mixture of binary qualitative (forest/bush, glade/closed-canopy) and continuous quantitative (PC1 and $\mathrm{PC}_{2}$ ) data. We used a backward elimination procedure of independent variables, progressively removing non-significant variables. Significance of the regression coefficients was tested using the Wald statistic, which is the square of the ratio of a regression coefficient to its standard error; this statistic follows a $\chi^{2}$ distribution (Legendre and Legendre 1998).

To analyse abundance data (counts), we used Poisson regressions with continuous independent variables ( $\mathrm{PC}_{1}$ and $\mathrm{PC}_{2}$ ); counts were converted to the $(\log x+1)$ scale. Non-parametric Kruskal-Wallis ANOVAs were used to test for differences in densities between forest and shrub, glades and closed-canopy, and seasons. Seasonal differences in altitudes were tested with one-way ANOVA.

The relative use of different foraging substrates was expressed as proportions, whilst height and relative height (height of the bird above ground/total height of substrate) were averaged. A $\chi^{2}$ test was performed to evaluate seasonal differences in the use of foraging substrates; one-way ANOVAs were carried out 
to test for seasonal differences in height and relative height (log-transformed data). The daylight hours were subdivided into three intervals (o6hoo-10hoo, 10ho1-15hoo, 15ho1-18hoo) to test, in each season, for diurnal differences in height and relative height (one-way ANOVAs on log-transformed data).

A Mann-Whitney $U$-test was used to look for seasonal differences in fruit location (height above ground), while $\chi^{2}$ test was performed to estimate the seasonal variation in the frequency of occurrence of fruiting plants within sample plots.

Feeding rates were compared between seasons and type of items collected (fruit/invertebrate) by a two-way ANOVA. Differences among habitat types (forest and shrub), time of day (three classes: 06hoo-10hoo, 10ho1-15hoo, 15ho118hoo), and flock size (10 individuals was arbitrarily chosen as a cut-off point for this analysis) were also investigated. Before carrying out parametric tests, feeding rates were $\log (x+1)$ transformed to attain a normal distribution. Flock size variations in relation to season, hour, habitat type and glade presence were analysed with Kruskal-Wallis ANOVAs. Sample size can differ between tests because of missing data (mostly when flock size could not be estimated). The use of parametric and non-parametric tests in the analyses depended on the ability to transform data in order to attain normal distribution.

Means are given \pm 1 Standard Error (SE) unless otherwise indicated.

\section{Results}

\section{Habitat use}

The first two PCA axes explained $58 \%$ of the variability of the habitat structure data-set $\left(P_{1}\right.$ : eigenvalue $=2.05, P_{2}$ : eigenvalue =2.03). PC 1 was positively correlated with the number of trees with a dbh $>20 \mathrm{~cm}$ (factor loading $=0.68$ ), negatively correlated with vegetation cover in the shrub layer (factor loading = -0.75 ) and with the number of trees with $\mathrm{dbh}<5 \mathrm{~cm}$ (factor loading $=-0.79$ ). PC2 was positively correlated with vegetation cover in the canopy and subcanopy strata (factor loadings $=0.67$ and 0.86 respectively) and negatively correlated to ground vegetation cover (factor loading $=-0.78$ ). PC 1 appeared to represent a positive gradient of old versus young tree abundance, but also had a negative correlation with vegetation cover in the low layers (whose density decreased as the forest was increasingly dominated by large trees). Conversely, vegetation density at medium-high layers provided the major loadings on PC2.

In the wet season, Kulal White-eye presence was positively correlated to glade presence and PC2 (canopy and subcanopy leaf cover), and negatively correlated to PCI (old tree abundance and minimum leaf cover in the shrub level; Table 1 ). In the dry period, only habitat type was a significant predictor of Kulal White-eye presence, as bush was avoided (Table 1 ).

Considering individual abundance, Poisson regressions with continuous predictors (PCI and PC2) revealed that in the dry season, they had no relationship with Kulal White-eye density, while in the wet season bird abundance was negatively correlated to PCI (Table 2).

In both seasons, densities of Kulal White-eye were higher in glades than in closed-canopy areas, although in the dry season the data were only marginally significant (dry season: Kruskal-Wallis ANOVA, $H(1,94)=3.4, P=0.06$; wet 
Table 1. Stepwise logistic regression of Kulal White-eye occurrence on environmental predictors.

\begin{tabular}{lcccc}
\hline & Estimate & SE & $\chi^{2}$ & $P$ \\
\hline Wet season & & & & \\
Constant & -1.01 & 0.25 & 16.90 & $<0.001$ \\
Glade/closed-canopy & 1.23 & 0.43 & 8.11 & $<0.005$ \\
PC1 & -0.43 & 0.21 & 4.15 & $<0.05$ \\
PC2 & 0.58 & 0.24 & 5.76 & $<0.05$ \\
Dry season & & & & \\
Constant & 0.59 & 0.63 & 1.10 & 0.35 \\
Forest/bush habitats & 1.28 & 0.63 & 4.20 & $<0.05$ \\
\hline Contins
\end{tabular}

Continuous structural variables were reduced by Principal Component Analysis to two continuous variables, PC1 and PC2. Model $\chi^{2}=12.7, P<0.005$ in the wet period, $\chi^{2}=4.30, P<0.05$ in the dry. Only variables that entered in the model are shown.

Table 2. Poisson regression of Kulal White-eye abundance on continuous environmental predictors in the wet period.

\begin{tabular}{lllcc}
\hline Variable & Estimate & SE & $\chi^{2}$ & $P$ \\
\hline Constant & -1.77 & 0.21 & 70.6 & $<0.001$ \\
PC 1 & -0.42 & 0.18 & 5.8 & $<0.05$ \\
PC2 & 0.26 & 0.22 & 1.3 & 0.25 \\
\hline
\end{tabular}

The seven structural variables were reduced by Principal Component Analysis to two continuous variables, $\mathrm{PC}_{1}$ and $\mathrm{PC}_{2}$, summarizing the major variability of the data set.

season: Kruskal-Wallis ANOVA, $H(1,125)=8.2, P<0.01$; Figure 1$)$. In the wet season no significant difference was found between densities in forest or bush (Kruskal-Wallis ANOVA, $H(1,173)=0.87$, n.s.; Figure 1), whilst in the dry period abundance was significantly lower in bush (Kruskal-Wallis ANOVA, $H(1,98)=4.8, P<0.05$; Figure 1$)$.

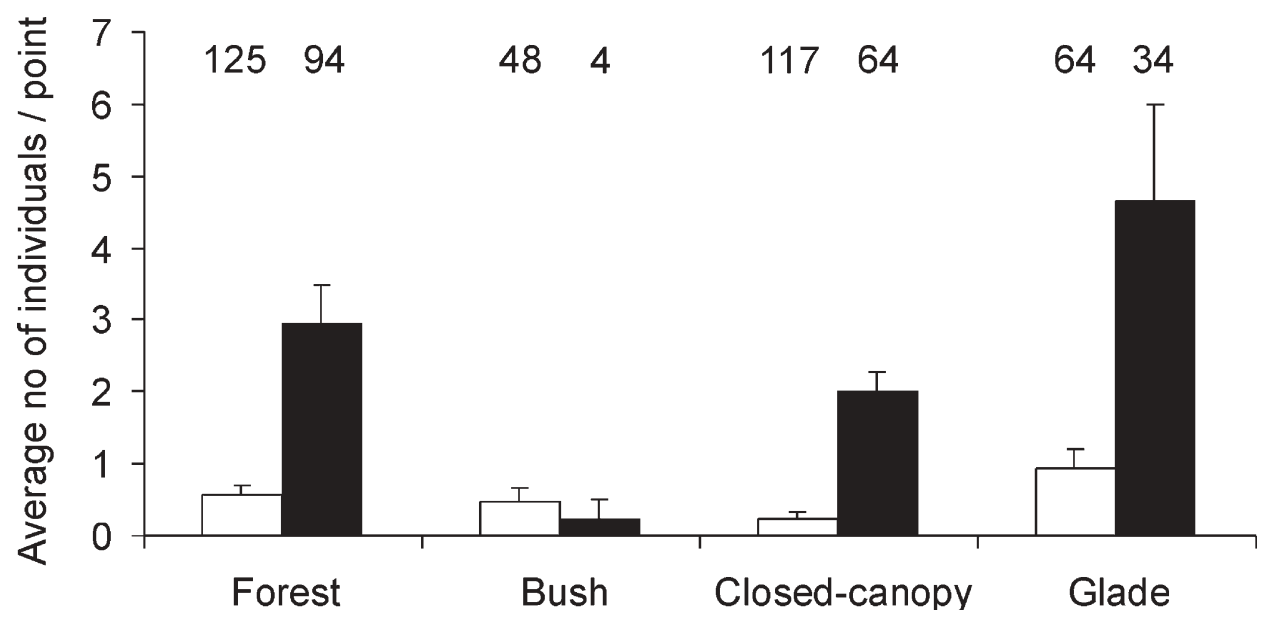

Figure 1. Average number of individuals $( \pm$ SE) of Kulal White-eye observed per sample point in different habitat types. White bars, wet seson; black bars, dry season. Sample sizes are given above each bar. 
Seasonal variations in density were analysed only in the forest, as almost no birds were found in the bush in the dry season. In both glades and closedcanopy areas, densities were significantly higher in the dry season than in the wet (glades: Kruskal-Wallis ANOVA, $H(1,90)=19.3, P<0.001$; closed-canopy: Kruskal-Wallis ANOVA, $H(1,129)=47.7, P<0.001$; Figure 1$)$.

On average, birds occurred at significantly lower elevation in the wet period (dry period: $1,957 \mathrm{~m}$ a.s.l. \pm 15 , wet period: $1,831 \mathrm{~m}$ a.s.l. $\pm 24, \mathrm{~F}_{1,147}=37.3$, $P<0.001 ; \log$ transformed data).

\section{Foraging ecology}

Considering all data together, $81 \%$ of observations were of individuals feeding on animal prey, $17 \%$ feeding on fruit and $2 \%$ on flower nectar. We found significant seasonal differences in all niche dimensions. In the dry season, birds foraged at significantly greater height $\left(\right.$ dry $=8.4 \mathrm{~m}$, wet $=4.8 \mathrm{~m}, \mathrm{~F}_{1,210}=34.4$, $P<0.001$ ) and relative height on plants (dry $=0.83$, wet $=0.73, \mathrm{~F}_{1,210}=9.3$, $P<0.005$ ), fed more frequently in the inner tree parts (twigs, moss) and on fruit, and spent less time searching among lichens and leaves (Figure 2). In the wet season, the height above ground increased progressively during the day (o6hoo-10hoo: $3.9 \mathrm{~m} \pm 0.4$, 10ho1-15hoo: $4.7 \mathrm{~m} \pm 0.4$, 15ho1-18hoo: $6.9 \mathrm{~m} \pm 1.1 \mathrm{o}$, $\left.\mathrm{F}_{2,108}=3.8, P<0.05\right)$. Conversely, no significant diurnal difference occurred in relative height, either in the wet or dry season.

Kulal White-eye fed on a larger number of fruiting plants during the dry season than during the wet (Table 3). Significant seasonal differences occurred in the vertical distribution of fruit (mean height of fruiting plants: dry season $=$ $11.4 \mathrm{~m} \pm 1.5$; wet season $=4.3 \mathrm{~m} \pm 0.3 \mathrm{~m}$. Mann-Whitney $U$-test: $U=28, P<0.001$,

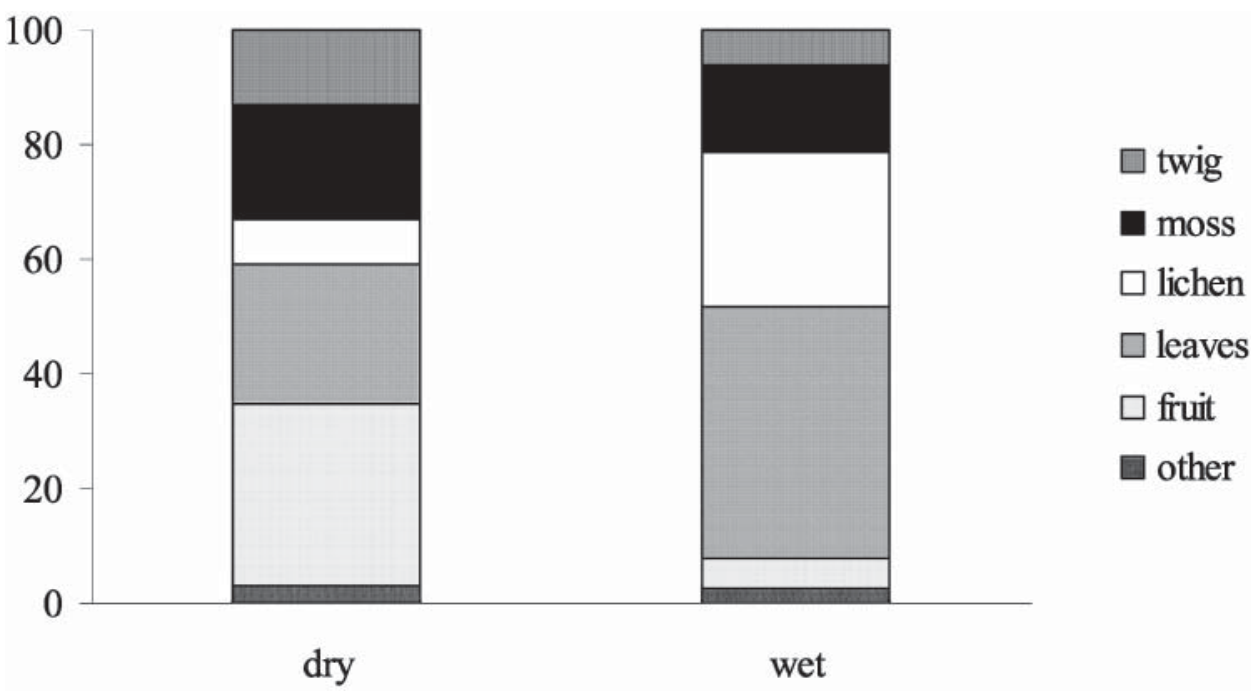

Figure 2. Percentage use of different food substrates in the wet and dry seasons by Kulal White-eye. Category "others" comprises nectar, branches, trunks, boughs and air. Differences between seasons are significant $\left(\chi_{4}^{2}=37.9, P<0.01 ; n=112\right.$ observations in the dry season, 100 in the wet). 
Table 3. Percentage use of fruiting plants by Kulal White-eye.

\begin{tabular}{llc}
\hline Species & Wet season & Dry season \\
\hline Ehretia cymosa & - & 30.0 \\
Doryalis abyssinica & - & 20.0 \\
Vitaceae sp. & - & 16.7 \\
Ficus thonningi & - & 6.7 \\
Cussonia holsti & - & $3 \cdot 3$ \\
Pistacia aethiopica & - & $3 \cdot 3$ \\
Ficus sur & - & $3 \cdot 3$ \\
Psychotria oreophila & - & $3 \cdot 3$ \\
Rhus natalensis & 20 & - \\
Pittosporum viridiflorum & 60 & - \\
Unidentified & 20 & $13 \cdot 3$ \\
\hline
\end{tabular}

Values represent percentages of feeding observations. Sample size: 30 observations in the dry season, 5 in the wet.

$n=73$ ). Fruiting plants were recorded with greater frequency in glades (glades: $22.8 \%$ of sample plots; closed-canopy $3.1 \%, n=271 ; \chi^{2}{ }_{1}=26.8, P<0.001$ ) and in the dry season (dry season $15.3 \%$ of sample plots; wet season $6.9 \%, n=271$; $\left.\chi_{1}^{2}=4.8, P<0.05\right)$.

\section{Foraging behaviour}

Flock size was highly variable (range 1-50 birds). In the dry season Kulal Whiteeye foraged in larger assemblages than in the wet (dry season: 8.1 $\pm 1.2, n=79$; wet season: $4.1 \pm 0.7, n=50$; Kruskal-Wallis ANOVA, $H(1,129)=4.4, P<0.05)$. Flock sizes were larger when the birds fed on fruit than when they fed on animal prey $(12.0 \pm 2.3$ and $4.8 \pm 0.5$ respectively; Kruskal-Wallis ANOVA, $H(1,125)=$ 14.1, $P<0.001)$. Significant diurnal differences in flock size occurred in the wet period, as larger aggregations occurred early and late in the day (average flock size: 06hoo-10hoo: 5.9 \pm 1.4 individuals; 10ho1-15hoo: $2.2 \pm 0.6$; 15ho1-18hoo: $4.6 \pm 1.1$; Kruskal-Wallis ANOVA, $H(2,50)=8.0, P=0.02)$. Mean flock size did not differ significantly between habitat types (forest and bush) or between glades and closed-canopy areas in both seasons (Kruskal-Wallis ANOVA, all $P>0.05$ ).

Kulal White-eye collected on average $3.1 \pm 0.2$ items per minute $(n=83)$. Feeding rates were significantly faster when birds collected fruits (Table 4 ), but no differences occurred between dry and wet periods. When only feeding on animal

Table 4. Peck rate (no. of items/min) by Kulal White-eye in the wet and dry seasons and with animal prey or fruit.

\begin{tabular}{lllll}
\hline & & Mean & SE & $n$ \\
\hline Season & Wet & 3.13 & 0.35 & 48 \\
& Dry & 2.97 & 0.33 & 35 \\
Food type & Fruit & 4.49 & 0.44 & 15 \\
& Animal prey & 2.74 & 0.27 & 68 \\
\hline
\end{tabular}

Differences were significant between food types (two-way ANOVA; $F_{1,79}=9.9, P<0.05$ ) but not between seasons or in the interaction (season $x$ food type). 
Table 5. Peck rate (no. of items/min) in the two habitat types and in flocks of different size $(\leq 10$ individuals and $>10$ individuals).

\begin{tabular}{llllll}
\hline & & Mean & SE & $n$ & One-way ANOVA \\
\hline Habitat type & Forest & 2.45 & 0.33 & 46 & $F_{1,66}=4.14, P<0.05$ \\
& Bush & 3.37 & 0.44 & 22 & \multirow{2}{*}{ Flock size } \\
& $<$ 1o birds & 2.70 & 0.37 & 38 & $F_{1,47}=4.04, P=0.05$ \\
& $>$ 1o birds & 3.85 & 0.52 & 11 & \\
\hline
\end{tabular}

Only data of birds feeding on animal prey are considered.

prey was considered, significant differences in peck rate occurred between habitat types and flock size classes (peck rates were higher in bush and when flocks were larger than 10 individuals), but no significant difference was found in feeding rates between different substrates and times of the day (Table 5). When birds collected fruits, peck rates were not significantly affected by habitat type, flock size classes and the time of day.

\section{Discussion}

\section{Habitat use}

In the dry period Kulal White-eye was encountered only in upper forest. Here, it reached higher densities in glades than in closed-canopy areas, but no other habitat structure descriptor was related to either occurrence or density of the species, which was abundant in all parts of the forest. A different pattern of habitat use was observed in the wet season, when many individuals left the upper forest to reach the drier bush at lower elevations. In the wet season, densities in the forest were higher in glades than in areas with continuous canopy, as was found in the dry months, but habitat structure correlated significantly with Kulal White-eye occurrence and density, as the species was less common in habitats with mature trees, and occurred more frequently in young tree formations with thicker vegetation.

The seasonal habitat and altitude shifts cause cyclic range expansions and contractions: in the dry periods birds concentrate in the forest on the top of the mountain, which, according to the available maps (Survey of Kenya 1:100.000, series Y633, sheet 41) extends over approximately 1,650 ha, while in the wet season they inhabit both the forest and the surrounding lower elevation bush (overall 7,100 ha, including forest). The lower densities recorded in forest in the wet period were probably associated with birds being scattered over a larger area at this time of the year.

\section{Foraging ecology}

The seasonal patterns of habitat use exhibited by Kulal White-eye could be explained by opportunistic adjustments in foraging behaviour, which in turn could reflect habitat productivity and the tracking of food resources available in the different seasons. Kulal White-eye was mostly insectivorous in the rainy season, when the flush of new foliage would be expected to support an increased 
production of insects (Janzen 1973, Brown and Britton 1980, Brosset 1990, Keast 1990). Conversely, a shift towards frugivory was recorded in the dry season, when we observed an increased abundance of fruiting plants. We found that fruiting trees were more frequent in glades, as has also been found in other studies (Blake and Hoppes 1986, Levey 1988). Higher food availability may therefore be an explanation for the higher abundance of Kulal White-eye in glades compared with closed-canopy areas.

The greater proportion of time spent foraging in the inner tree parts (twigs, moss clumps) in the dry months might be associated with the tendency of invertebrates to seek the inner and wetter portions of trees to escape desiccation. During the rains, Kulal White-eyes shifted to lower altitude bush habitats, where they probably tracked abundant seasonal food resources. This hypothesis is supported by the significantly higher prey-attack rates recorded in this habitat, suggesting that foraging in the bush was more effective than in the forest. The increased invertebrate prey production associated with leaf flush in the wet season could explain why birds kept in dense foliage in this period. Moreover, Kulal White-eyes seem to adjust their vertical distribution in concert with changing food availability: in the dry period, birds tended to forage in the upper layers of the forest, where most fruits were located, whilst they occurred mostly in the dense vegetation of the middle strata of forest in the wet period. We also found an increase in perch height (but not in relative height) during the day in the wet season, which suggests a preference for lower vegetation (shrubs) in the morning and higher trees later in the day. This might again be related to shifts in the distribution of invertebrate prey, although we have no data to test this hypothesis.

Summing up, although our study is only correlative, our findings are consistent with the hypothesis that seasonal habitat and microhabitat shifts in Kulal White-eye could be determined by the tracking of food resources, which appear to vary with time of year. Resource tracking has often been indicated as one of the principal reasons for explaining birds' movements and seasonality in the tropics (Blake and Loiselle 1991, Loiselle and Blake 1991, Whitney and Smith 1998, Borghesio and Laiolo 2004), but other factors such as micro climate variation, nest site availability or predator avoidance might also be important (Karr and Freemark 1983, Cody 1985).

\section{Foraging behaviour}

Kulal White-eye occurred alone or in groups of up to 50 individuals. Flock size varied significantly between seasons, and changed during the day (only in the wet season) and according to food type selected. As ringing data suggest that reproduction occurs in the rainy period (Borghesio and Ndang'ang'a 2001), it is not surprising that large flocks split up into pairs or small parties as the breeding season approached. However, as larger groups were observed when birds fed on fruit, and fruit were available mostly during the dry season, it is also possible that the higher flock size observed in the dry season might be a consequence of a tendency of the birds to congregate on single large fruiting trees. In the wet period, observations of large flocks early and late in the day were possibly associated with birds' habits: they appeared to roost in forest interior at night, 
emerging as large flocks in the morning and moving to surrounding habitats (bush, glades), where they split into smaller foraging groups.

Fruits were picked up faster than invertebrate prey, even if such efficiency was likely to be balanced by the proportionally lower calorific content of vegetable items (Bairlein 1996).

When birds collected invertebrate prey, birds in small flocks ( $\leq 10$ individuals) had lower feeding rates than those foraging in larger flocks. Several studies have shown that foraging in large flocks is advantageous: individuals in large groups would take advantage of the vigilance of other group members, scan less frequently and, as a consequence, have more time to feed (Pulliam 1973). Nevertheless, Catteral et al. (1992) showed that there was no relationship between scanning behaviour and group size in Silvereyes Zosterops lateralis, i.e. larger groups did not spend less time scanning (and more time feeding). It should be stressed, however, that Silvereyes were studied in a predator-free environment, and covariation between group size and vigilance is not expected in the absence of predators.

\section{Conclusion and conservation implications}

This study emphasizes that Kulal White-eye has great behavioural flexibility. This flexibility coincides with "opportunism" rather than "generalism", because the species seems to specialize in the food and habitat type that is more readily available in each season. Nevertheless, our results indicate that this species is less restricted to mature forest than previously thought. Old primary forest tends to be avoided by foraging birds in the wet season, but it could be important for roosting and sheltering at night. In any case, the existence of seasonal shifts towards non-forest habitats stresses that the preservation of Kulal White-eye requires focusing on a much larger area than that occupied by forest alone.

BirdLife International (2000) emphasized that Kulal White-eye requires full protection and recognition of its threatened status, because it is currently confined to a very restricted range. We found that bush habitats, particularly important to Kulal White-eye in the critical period of breeding, are subject to increasing loss and degradation due to the intensification of land use by local people, through burning, clearance and grazing (Herlocker 1979). It is not likely that these practices could completely destroy this habitat, whose vegetation is fire-adapted and resistant to grazing. However, in the long run they could degrade natural vegetation, thus making it less attractive to Kulal White-eye. At present, dense bushland is still abundant on Mount Kulal and human activity and habitat damage are concentrated on the most accessible areas near settlements, but as the human population in the area steadily expands, the impact on the bushland is likely to increase.

In the forest, population density of Kulal White-eye was significantly higher in glades than in closed-canopy areas. It is likely that in the past many glades were created by large mammals (African buffalo Syncerus caffer, African elephant Loxodonta Africana; Chapman and Chapman 1996), which contributed to maintaining a favourable habitat for Kulal White-eye. However, since the early 1970s, large mammals have been exterminated in the area, and one possible consequence of their disappearance could be an increase in canopy closure, which could cause a deterioration of the forest habitat for Kulal White-eye. 
Human activities can also have effects on the forest. In particular, overgrazing by cattle and goats tends to destroy the shrub layer and prevent plant regeneration (Reed et al. 2000), which in the long run might determine the disappearance of the forest. In recent years, due to a series of droughts and the increase of human population, livestock presence in the forest of Mt Kulal has increased. On Mount Nyiru (70 km S of Kulal), where human density is higher and the forest has been used as pasture for cattle and goats for several years, damage to the forest is already extensive: the undergrowth is almost absent and large, grassy glades are progressively reducing the extent of forest (L. Borghesio and P. Laiolo unpubl. data). At present, the situation on Mt Kulal is better than on Nyiru, but an increase in the density of domestic herbivores in the area should not be favoured.

In conclusion, we suggest that in order to conserve Kulal White-eye, it is essential to maintain the mixture of forest, small glades and dense shrub vegetation that currently characterize the Mt Kulal landscape. This could be done by managing and balancing natural succession processes, selective tree cutting (as is currently practised by local people), grazing of domestic animals and fire events. It is unquestionable that strategies for influencing land-use need to consider local demands: any action to preserve the habitat must consider the increasing need for agricultural and pasture land and the interests of local people. We suggest that wild honey collection and a limited amount of selective tree cutting could be carried out sustainably, while grazing by goats and cattle will have detrimental effects and should not be allowed to increase. The extent to which Kulal Whiteeye can adjust its behaviour in response to human impact is likely to be a key factor in determining its survival in disturbed habitats, and further studies on this topic should be encouraged, to determine the levels of forest exploitation that are sustainable with respect to the species ecology, and whether these are likely to be exceeded now or in the near future.

\section{Acknowledgements}

We wish to thank Leon Bennun, Kariuki Ndang'ang'a and all the staff of the Ornithology Department, National Museum of Kenya, Don Turner and Graeme Backhurst of the East African Natural History Society, Renato Massa and Aldo Zullini of the University of Milan, Esau Omollo of the Kenya Forest Department, Renato Giuliani and our guides, Mamo Mosor, Mohamed Chukri, William Lepukey, Antony Lemeteki and Kipsoi Labria. Adrian Craig and Norbert Cordeiro made useful comments on an early version of the manuscript. The research was carried out under research permit No OP/13/oo1/27 $3 / 2$ issued by the Office of the President of the Republic of Kenya. Funding was provided by a fellowship awarded to Luca Borghesio by the University of Milan, Italy.

\section{References}

Bairlein, F. (1996) Fruit-eating in birds and its nutritional consequences. Comp. Biochem. Physiol. 113: 215-224.

Bake, G. (1983) An analysis of climatological data from the Marsabit District of northern Kenya. IPAL Technical Paper Number B-3. UNESCO-MAB Integrated Project in Arid Lands. 
BirdLife International. (2000) Threatened birds of the world. Barcelona and Cambridge, U.K.: Lynx Edicions and BirdLife International.

Blake, J. G. and Hoppes W. G. (1986) Resource abundance and microhabitat use by birds in an isolated East-central Illinos woodlot. Auk 103: 328-340.

Blake, J. G. and Loiselle B. A. (1991) Variation in resource abundance affects capture rates in three lowland habitats in Costa Rica. Auk 108: 114-130.

Borghesio, L. and Laiolo, P. (2004) Seasonal foraging ecology in a northern Kenya forest avifauna. J. Trop. Ecol. in press.

Borghesio, L. and Ndang'ang'a, P. K. (1999) Threatened birds of Kenya 11: Kulal White-eye. Kenya Birds 7: 75-77.

Borghesio, L. and Ndang'ang'a, P. K. (2001) An avifaunal survey of Mt Kulal, Kenya. Scopus 22: 1-12.

Britton, P. (Ed.) (1980) Birds of East Africa. Nairobi : East Africa Natural History Society.

Brosset, A. (1990) A long term study of the rain forest birds in M'Passa (Gabon). Pp. 109-121 in: A. Keast, ed. Biogeography and ecology of forest bird communities. The Hague: SPB Academic Publishing.

Brown, L. H. and Britton, P. L. (1980) The breeding season of East African birds. East Africa Natural History Society, Nairobi, Kenya

Burgess, N. D. and Mlingwa, C. O. F. (2000) Evidence for altitudinal movements of birds in the Eastern Arc montane and lowland forests of East Africa. Ostrich 71: 184-190.

Catteral, C. P., Elgar, M. A. and Kikkawa, J. (1992) Vigilance does not covary with group size in an island populations of silvereyes (Zosterops lateralis). Behav. Ecol. 3: 207-210.

Chapman, C. A. and Chapman, L. J. (1996) Mid-elevation forests: a history of disturbance and regeneration. In: T. R. McClanahan and T. P. Young, eds. East African ecosystems and their conservation. New York: Oxford University Press.

Cody, M. L., ed. (1985) Habitat selection in birds. Orlando, FL: Academic Press.

Collar, N. J., Crosby, M. and Stattersfield, A. J. (1994) Birds to watch 2: the world list of the threatened birds. Cambridge, U.K.: BirdLife International. (BirdLife Conservation Series 4.)

Diamond, A. W. and Keith, G. S. (1980) Avifaunas of Kenya forest islands. I. Mount Kulal. Scopus 4: 49-56.

Dowsett-Lemaire, F. (1980) Ecological and biogeographical aspects of forest bird communities in Malawi. Scopus 13: 1-80.

Edwards, K. A., Field, C. R. and Hogg, I. G. (1979) A preliminary analysis of climatological data from the Marsabit district of northern Kenya. IPAL Technical Paper Number B-1. UNEP-MAB Integrated Project in Arid Lands.

Fry, C. H., Urban, E. K. and Keith, S., eds. (2001) Birds of Africa, Vol. VI. Harcourt International. U.K.

Herlocker, D. (1979) Vegetation of southwestern Marsabit District, Kenya. IPAL Technical Report Number D-1. UNEP-MAB Integrated Project in Arid Lands.

Howard, R. and Moore, A. (1991) A complete checklist of the birds of the world. Second edition. London: Academic Press.

Janzen, D. H. (1973) Sweep samples of tropical foliage insects: effects of seasons, vegetation types, elevation, time of the day, and insularity. Ecology 54: 687-708.

Jongman, R. H. G., ter Braak, C. J. F. and Van Tongeren, O. F. R. (1995) Data analysis in community and landscape ecology. Cambridge, U.K.: Cambridge University Press.

Karr, J. R. and Freemark K. E. (1983) Habitat selection and environmental gradients: dynamics in the "stable" tropics. Ecology 64: 1481-1494.

Keast, A., ed. (1990) Biogeography and ecology of forest bird communities. The Hague: SPB Academic publishing.

Legendre, P. and Legendre, L. (1998) Numerical ecology. Amsterdam: Elsevier Science. 
Levey, D. J. (1988) Spatial and temporal variation in Costa Rican fruit and fruit eating bird abundance. Ecol. Monogr. 58: 251-269.

Lewis, A. and Pomeroy, D. (1989) A bird Atlas of Kenya. Rotterdam: A. A. Balkema.

Loiselle, B. A. and Blake, J. G. (1991) Temporal variation in birds and fruits along an elevational gradient in Costa Rica. Ecology 72: 180-193.

Moreau, R. E. (1957) Variation in the western Zosteropidae (Aves). Bull. Brit. Muse. Nat. Hist. (Zoology) 4: 309-433.

Pulliam, H. R. (1973) On the advantages of flocking. J. Theoret. Biol. 38: 419-422.

Reed, M. S. and Clokie, M. R. J. (2000) Effects of grazing and cultivation on forest plant communities in Mount Elgon National Park, Uganda. Afr. J. Ecol. 38: 154-162.

Whitney, K. D. and Smith, T. B. (1998) Habitat use and resource tracking by African Ceratogymna hornbills: implications for seed dispersal and forest conservation. Anim. Conserv. 1: 107-117.

\section{LUCA BORGHESIO}

C. Re Umberto 42, 10128, Torino, Italy, and Department of Ornithology, National Museum of Kenya, Box 40658, Nairobi, Kenya. E-mail: borghesio@libero.it

\section{PAOLA LAIOLO}

Dipartimento di Biologia Animale e dell'Uomo, Turin University, Via Accademia Albertina 17, Turin, Italy. E-mail: paola.laiolo@unito.it

Received 17 October 2002; revision accepted 23 September 2003 